\title{
CDISC SEND Null Flavor Reason Terminology
}

National Cancer Institute

\section{Source}

National Cancer Institute. CDISC SEND Null Flavor Reason Terminology. NCI Thesaurus.

Code C150810.

The terminology that includes concepts relevant to the Clinical Data Interchange Standards Consortium (CDISC) Standard for the Exchange of Non-clinical Data (SEND) null flavor. 